\title{
Editorial
}

\section{A Qualidade da Publicação Científica}

O ciclo do conhecimento científico envolve duas etapas essenciais. A primeira é a produção do conhecimento, que envolve a elaboração do problema a ser investigado, a seleção de uma metodologia adequada para tal investigação, a condução da própria investigação e a análise e interpretação dos resultados obtidos. A segunda é a divulgação do conhecimento, que, comumente, compreende palestras em reuniões científicas e visitas a centros de pesquisa, dentre outros meios, mas que só é plenamente realizada por meio da publicação em periódico especializado. Isso porque, ao ser enviado a um periódico, o manuscrito é submetido à "revisão pelos pares" e sua aprovação só se dá caso atenda critérios mínimos de excelência. Mas a publicação, em si, não garante a qualidade do conhecimento, sendo crucial que o mesmo desperte questionamentos em outros pesquisadores, promova novos trabalhos e, assim, contribua para o desenvolvimento da área. Em ambas etapas, produção e divulgação, esperase que o comportamento dos atores envolvidos (autores, consultores, editores etc.) implique compromisso irrestrito com normas éticas.

Nos últimos anos, o número de artigos submetidos a publicação cresceu vertiginosamente no país. Parte desse crescimento se deveu a mudanças no sistema de avaliação de programas de pós-graduação adotado pela CAPES, que passou a priorizar a produtividade (leia-se: o número de publicações) dos pesquisadores afiliados a esses programas. Mais recentemente, no entanto, em virtude da oposição da comunidade científica nacional ao "produtivismo", e também em decorrência do que ocorre no âmbito internacional, o sistema de avaliação passou a incorporar outros indicadores de qualidade da produção, tornando-se crucial para o sistema o chamado "fator de impacto". Esse indicador aponta o quanto um periódico contribui para o crescimento de uma área, o que é mensurado a partir do número de citações dos artigos nele publicados. Assim, quanto maior o número de citações, maior a influência do conhecimento publicado e, consequentemente, maior a sua relevância.

O uso do fator de impacto nas avaliações da CAPES também tem sido criticado, mas discutir essas críticas foge ao objetivo do presente editorial. Na verdade, nosso objetivo aqui é discutir brevemente a contribuição de cada ator do ciclo do conhecimento científico para a qualidade das publicações. Essa discussão parece relevante em virtude do que vem ocorrendo no cenário da publicação científica. Mais especificamente, as cobranças relacionadas ao número de publicações têm gerado algumas consequências danosas. Numa tentativa de atender a tais cobranças, alguns pesquisadores têm submetido a publicação (e, não raramente, têm conseguido publicar) manuscritos pouco ou nada originais (alguns não acrescentam nada à literatura, limitando-se a "dizer a mesma coisa de outra forma"), com fragilidades na consistência lógica dos argumentos e na metodologia empregada e/ou com exageros inaceitáveis acerca do âmbito das conclusões alcançadas; alguns, ainda, têm conferido autoria indevida a colegas e até mesmo cometido plágio (Werneck, 2006).

Como autores, consultores e editores podem tentar amenizar esse cenário? Em relação ao autor, é preciso que o mesmo conheça amplamente a literatura da sua área de investigação (e, idealmente, de áreas afins), discuta seu projeto de pesquisa com colegas (vale lembrar que os alunos de graduação e de pós-graduação comumente oferecem sugestões inestimáveis para o aprimoramento do projeto), submeta seu projeto à apreciação por comitês de ética e comitês de avaliação de órgãos de fomento, relate todos os dados obtidos (mesmo aqueles que desafiam suas hipóteses) e, caso haja motivos para questionar a fidedignidade e validade do estudo, aprimore o controle experimental antes de submeter o manuscrito a publicação.

Ao preparar o manuscrito, alguns cuidados são recomendados ao autor:

(a) ter muito zelo com a redação, tanto no que diz respeito ao seguimento das normas da língua utilizada, como no que tange à estrutura lógica do texto (um bom conteúdo pode se perder numa redação precária);

(b) incluir publicações relevantes, mesmo aquelas contrárias às suas conclusões;

(c) apresentar uma justificativa convincente para a elaboração de seu estudo;

(d) evitar redundâncias e/ou ambiguidades na análise dos dados (com tabelas e figuras eficientes, os resultados "saltam aos olhos" do leitor, dispensando a leitura da descrição dos mesmos);

(e) comparar, com o máximo de imparcialidade, seus resultados com aqueles já apontados na literatura, mostrando consistências e inconsistências, as quais devem ser justificadas;

(f) seguir rigorosamente as normas de publicação do periódico escolhido (o não seguimento dessas normas pode levar à rejeição do manuscrito antes mesmo de ser iniciado o processo de revisão pelos pares);

(g) escolher um periódico renomado, pois isso reduz as chances de erros formais e lógico-estruturais em seu manuscrito, devido aos critérios rígidos adotados no processo de revisão (Volpato \& Freitas, 2003), além de aumentar as chances de disseminação do conhecimento produzido;

(h) ser criterioso ao definir a autoria do trabalho; embora não haja critérios universalmente aceitos, é importante que os autores e co-autores tenham contribuído intelectualmente para o conteúdo do artigo, tornando-se responsáveis pelo mesmo (Feitosa, 1994a);

(i) solicitar uma revisão preliminar do manuscrito a um colega;

(j) nunca encaminhar o manuscrito para mais de um periódico. 
Os consultores também podem contribuir substancialmente para a qualidade da publicação por meio da emissão de pareceres fundamentados. Não basta recomendar a aceitação, reformulação ou rejeição do manuscrito. No caso de aceitação, as justificativas devem indicar, dentre outras coisas, a contribuição específica do estudo para o crescimento da área. No caso de reformulação ou de rejeição, o parecer deve identificar as falhas encontradas e sugerir estratégias para sua correção (uma recomendação de rejeição diferenciase da recomendação de reformulação na medida em que aponta, dentre outros aspectos, vulnerabilidades lógicas e/ ou metodológicas que inviabilizam quaisquer conclusões). A título de exemplo: não basta indicar que não são citados autores relevantes; é preciso indicar quais são esses autores; não basta apontar que as tabelas e/ou figuras não são adequadas; é preciso sugerir formas de corrigi-las; não basta dizer que os resultados não foram comparados com aqueles apontados na literatura; é preciso fornecer um exemplo de tal relação. Além de fornecer críticas construtivas, cabe ao consultor evitar o conservadorismo teórico-conceitual e/ou metodológico na avaliação de manuscritos e reconhecer os limites da sua competência (Silva, 2006).

Outra contribuição importante do consultor é a prontidão no fornecimento do parecer. Infelizmente, o processo de revisão pelos pares compreende muitas práticas que têm gerado um atraso substancial na tramitação de um manuscrito. É comum, por exemplo: o consultor não responder à solicitação de emissão de um parecer; o consultor confirmar sua disponibilidade para emitir o parecer, mas não o enviar, nem mesmo diante de inúmeras mensagens de cobrança; o consultor confirmar sua disponibilidade, mas enviar o parecer com muito atraso; o parecer ser enviado apenas com a recomendação geral, sem nenhuma fundamentação, o que o torna estéril e, consequentemente, requer a solicitação de um parecer adicional. Inúmeras são as motivações do consultor em tais situações. Elas não serão aqui discutidas, mas vale ressaltar três aspectos:

(a) o atraso na emissão do parecer pode trazer prejuízos diretos para os autores, que dependem de uma certa taxa de publicação para terem direito a promoções, financiamentos de pesquisas e de participação em congressos etc., bem como para o periódico, que passa a ser mal visto por autores e avaliadores em função do longo período entre submissão e publicação do manuscrito;

(b) um parecer favorável à publicação, mas emitido com atraso, pode resultar na publicação de artigos com literatura desatualizada e até mesmo com resultados obsoletos;

(c) um pesquisador ora é consultor, ora é autor, de modo que, ao desempenhar com eficiência ambos os papéis, estará contribuindo não somente para a melhora de seu currículo, mas principalmente para a qualidade da publicação científica (Volpato \& Freitas, 2003).

E o editor? Qual seu papel no processo de publicação? Inicialmente, é importante esclarecer que, embora os pareceres sejam uma parte essencial do processo de publicação, sua contribuição consiste em fornecer subsídios para a decisão final, a qual é de responsabilidade do editor. Diante de tamanha responsabilidade e do compromisso com a inovação e a originalidade do conhecimento, cabem ao editor inúmeras tarefas. Dentre elas, conforme apontado por Feitosa (2004b), destacam-se:

(a) adotar normas de publicação rigorosas, que permitam a seleção de artigos de qualidade inquestionável;

(b) selecionar consultores de forma cuidadosa, de modo a evitar injustiças decorrentes de divergências teóricas, metodológicas etc.;

(c) utilizar procedimentos de tramitação padronizados, que impeçam a ocorrência de privilégios e preferências;

(d) garantir a independência intelectual dos autores e consultores;

(e) não participar da tramitação de manuscritos de sua autoria;

(f) contornar erros de publicação por meio de erratas, por exemplo;

(g) impedir que informações presentes no manuscrito (e nos pareceres) sejam utilizadas pelos participantes do processo de tramitação antes de sua publicação;

(h) assegurar a atualidade do material publicado.

Outros autores acrescentam que o editor deve incentivar a publicação em inglês com o objetivo de aumentar a penetração do conhecimento produzido no país no cenário internacional (e.g., Volpato \& Freitas, 2003).

Em suma, o processo de divulgação do conhecimento é, indubitavelmente, laborioso. Requer comprometimento com a ética e com os objetivos da ciência, disponibilidade inestimável de tempo, perseverança e lucidez no dia-a-dia da investigação, excelência na redação de textos, sofisticação intelectual etc. Mas, se todos os integrantes desse processo cumprirem suas tarefas com responsabilidade e presteza, certamente o processo será menos árduo e melhores resultados serão alcançados. Esse deve ser um compromisso de todos.

Os artigos publicados no presente número, o primeiro do volume 25, certamente refletem esse compromisso. No contexto da Psicologia Escolar, Kelly Cristine Placha e Maria Lucia Faria Moro analisam as relações entre intervenções de ensino e a aprendizagem de soluções de caráter combinatório para problemas de produto cartesiano em crianças. Paulo Celso Pereira, Adriana Barbosa dos Santos e Lúcia Cavalcanti de Albuquerque Williams indicam que crianças vítimas de violência doméstica apresentam um desempenho escolar inferior àquele de crianças não vitimizadas.

$\mathrm{Na}$ área de Psicologia do Desenvolvimento, Luciana Mian, Louise Azenha Tango, Juliana Lopes e Sonia Regina Loureiro avaliam os efeitos da depressão materna sobre o comportamento de crianças em idade escolar. Rosana Maria Freitas de Lemos, Lorena Ribeiro dos Santos e Fernando Augusto Ramos Pontes discutem a percepção de adolescentes acerca de seus encontros familiares. As tarefas de cuidado de irmão/ã de criança com paralisia cerebral são analisadas por Moema P. G. Soares, Anamélia L. S. Franco e Ana M. A. Carvalho.

No âmbito da Psicologia da Saúde, Florêncio Mariano da Costa-Júnior e Ana Cláudia Bortolozzi Maia averiguam as concepções sobre gênero e saúde/adoecimento de homens hospitalizados e enfatizam a necessidade de políticas públicas de saúde voltadas especificamente para a população masculina. As emoções e episódios da vida diária que ocorrem simultaneamente a arritmias cardíacas de indivíduos sub- 
metidos ao exame de Holter 24 horas são investigados por Ana Myriam Sánchez Bonomo e Tereza Cristina Cavalcanti Ferreira de Araújo. Finalmente, Ingrid Duarte Pinto, Flávia Helena Pereira Padovani e Maria Beatriz Martins Linhares apontam que emoções e sentimentos negativos acerca de bebês prematuros são mais comuns em mães com sintomas clínicos de ansiedade e depressão do que em mães sem tais sintomas.

No contexto clínico, Samara Silva dos Santos e Débora Dalbosco Dell'Aglio mostram que as mães de crianças vítimas de abuso sexual tendem a acreditar no relato das filhas e a denunciar o abuso. Célia G. Oliveira e Pedro B. Albuquerque apresentam uma revisão da literatura sobre o Transtorno de Déficit de Atenção e Hiperatividade, ressaltando possíveis fatores responsáveis pela diversidade de dados e conclusões. Em outro artigo de revisão, Berenice Victor Carneiro e Elisa Medici Pizão Yoshida discutem o conceito de alexitimia, com ênfase nas recentes contribuições da neurobiologia.

Ana Maria Nicolaci-da-Costa apresenta a transformação no significado de algumas palavras e discute as implicações dessa transformação para a psicologia. Luciano Meira e Flávia Peres discutem como as ações de desenvolvedores e usuários de softwares regulam um ao outro enquanto sujeitos das relações humano-computador. Finalmente, na área de Análise do Comportamento, Carolina Laurenti e Carlos Eduardo Lopes argumentam a favor da identidade entre explicação e descrição no Behaviorismo Radical, enquanto
Nicolau Chaud de Castro Quinta e Cristiano Coelho avaliam se o fornecimento de feedbacks após julgamentos acerca da veracidade de um evento promove o aprimoramento da habilidade de detecção de mentiras.

Boa leitura!

\section{Josele Abreu-Rodrigues \\ Editora}

\section{Referências}

Feitosa, M. A. G. (1994a). A responsabilidade ética do autor de manuscritos submetidos a publicação [Editorial]. Psicologia: Teoria e Pesquisa, 10, iv-viii.

Feitosa, M. A. G. (1994b). A responsabilidade ética do editor de um periódico científico [Editorial]. Psicologia: Teoria e Pesquisa, 10, iv-viii.

Silva, J. M. (2006). Aspectos éticos e funcionais da publicação científica: passado, presente e futuro. Interacções, 3, 19-31.

Volpato, G. L., \& Freitas, E. G. (2003). Desafios na publicação científica. Pesquisa Odontológica Brasileira, 17 (1, Suplemento), 49-56.

Werneck, G. L. (2006). Ética na publicação científica [Editorial]. Cadernos de Saúde Coletiva, 14, 5-6. 